Keywords: 9975, package packaging, beetles

Retention: Permanent

\title{
Detection of Drugstore Beetles in 9975 Packages using Acoustic Emissions
}

D. J. Shull

February 2013

Savannah River National Laboratory Savannah River Nuclear Solutions, LLC Aiken, SC 29808

Prepared for the U.S. Department of Energy under contract number DE-AC09-08SR22470. 
SRNL-STI-2013-00091

Revision 0

\section{DISCLAIMER}

This work was prepared under an agreement with and funded by the U.S. Government. Neither the U.S. Government or its employees, nor any of its contractors, subcontractors or their employees, makes any express or implied:

1. warranty or assumes any legal liability for the accuracy, completeness, or for the use or results of such use of any information, product, or process disclosed; or

2. representation that such use or results of such use would not infringe privately owned rights; or

3. endorsement or recommendation of any specifically identified commercial product, process, or service.

Any views and opinions of authors expressed in this work do not necessarily state or reflect those of the United States Government, or its contractors, or subcontractors.

\section{Printed in the United States of America}

Prepared for

U.S. Department of Energy 


\section{REVIEWS AND APPROVALS}

AUTHORS:

Signature on File

$3 / 1 / 2013$

D. J. Shull, R \& D Engineering

Date

TECHNICAL REVIEW:

Signature on File

$3 / 1 / 2013$

W. L. Daugherty, Materials Science \& Technology

Date

APPROVAL:

Signature on File

$3 / 1 / 2013$

G. E. Weeks, Manager

Date

Instrumentation \& Electronic Development

Signature on File

$3 / 1 / 2013$

S.L. Tibrea, Manager

Date

R \& D Engineering

Signature on File

$3 / 4 / 2013$

E. R. Hackney

Date

KAC Process Systems 


\section{EXECUTIVE SUMMARY}

This report documents the initial feasibility tests performed using a commercial acoustic emission instrument for the purpose of detecting beetles in Department of Energy 9975 shipping packages. The device selected for this testing was a commercial handheld instrument and probe developed for the detection of termites, weevils, beetles and other insect infestations in wooden structures, trees, plants and soil.

The results of two rounds of testing are presented. The first tests were performed by the vendor using only the hand-held instrument's indications and real-time operator analysis of the audio signal content. The second tests included hands-free positioning of the instrument probe and post-collection analysis of the recorded audio signal content including audio background comparisons.

The test results indicate that the system is promising for detecting the presence of drugstore beetles, however, additional work would be needed to improve the ease of detection and to automate the signal processing to eliminate the need for human interpretation. Mechanisms for hands-free positioning of the probe and audio background discrimination are also necessary for reliable detection and to reduce potential operator dose in radiation environments. 


\section{TABLE OF CONTENTS}

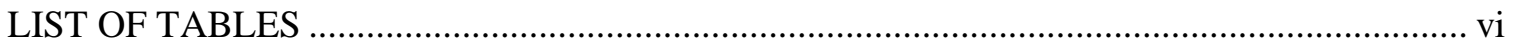

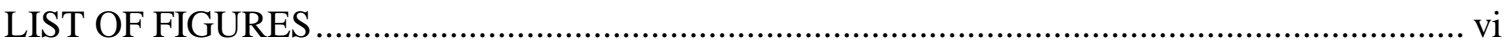

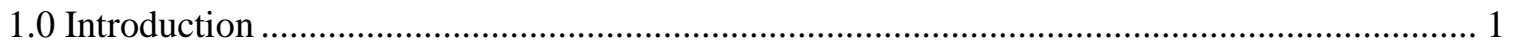

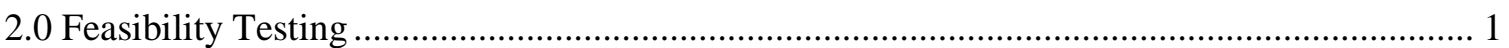

2.1 Demonstration and Testing by Instrument Vendor........................................................ 1

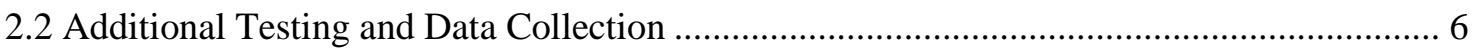

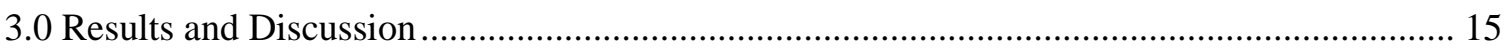

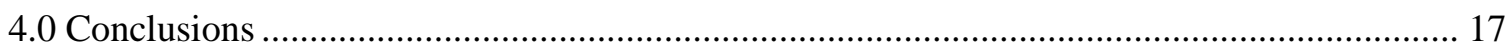

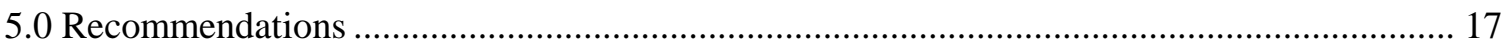

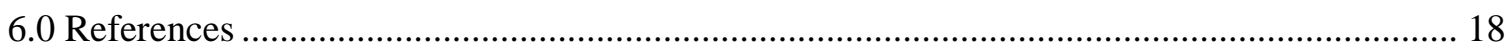


SRNL-STI-2013-00091

Revision 0

\section{LIST OF TABLES}

Table 2-1. Catalog of Recordings.

\section{LIST OF FIGURES}

Figure 2-1. Mr. John Rodgers of Acoustic Emission Consulting with Portable Insect Detection

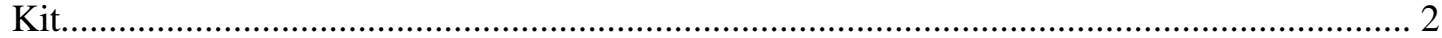

Figure 2-2. Acoustic Emission Consulting Portable Insect Detection Kit ................................... 3

Figure 2-3. Acoustic Emission Consulting AED-2010L Instrument and SP-1L Probe ................. 3

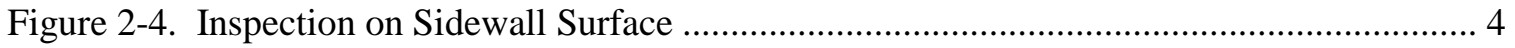

Figure 2-5. Probe Coupled to Celotex ${ }^{\mathrm{TM}}$ Using Drill Bit Adapter ................................................ 4

Figure 2-6. Drill Bit Inserted into Celotex ${ }^{\mathrm{TM}}$ in Top Cap........................................................... 5

Figure 2-7. Probe Coupled to Celotex ${ }^{\mathrm{TM}}$ in Top Cap Using Drill Bit Adapter ............................. 5

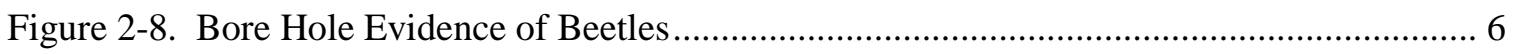

Figure 2-9. Data Collection Instrumentation for Recorded Measurements.................................. 8

Figure 2-10. Audio Mixing Console used for Signal Conditioning ........................................... 8

Figure 2-11. Hands-free Positioning of Detector Probe with Microphone Boom Stand................ 9

Figure 2-12. Placement at Approximately 4 Inches from Bottom of Packaging.......................... 10

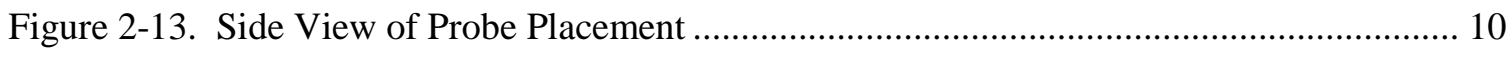

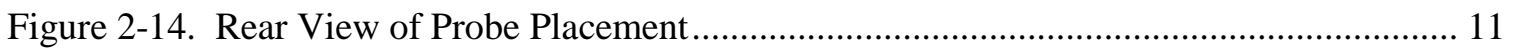

Figure 2-15. Audacity Digital Audio Editor Software Screenshot............................................. 12

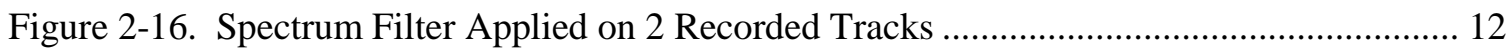




\section{LIST OF ABBREVIATIONS}

AEC Acoustic Emission Consulting, Inc

DOE

Department of Energy

KAC

K-Area Complex

MP3

Motion Picture Experts Group MPEG-1 or MPEG-2 Audio Layer III

SRNL

Savannah River National Laboratory

USDA

United States Department of Agriculture 


\subsection{Introduction}

The presence of drugstore beetles (Stegobium paniceum (L.) Coleoptera: Anobiidae) in Department of Energy 9975 shipping packages has been previously documented (Loftin, Shuler, Bellinger, \& Abramczyk, 2008; Loftin \& Shuler, 2010). The long term effects of beetle damage on the Celotex ${ }^{\mathrm{TM}}$ fiberboard insulation material are unknown at this time. A non-destructive insitu method of beetle detection in the 9975 shipping packages is desirable. This report documents the initial feasibility tests performed using a commercial acoustic emission instrument for beetle detection. The product chosen for these tests is a commercial handheld instrument and probe that has been developed for the detection of termites, weevils, beetles and other insect infestations in wooden structures, trees, plants and soil.

Several thousand 9975 shipping packages are used as part of the approved storage configuration of special nuclear material in K-Area Complex (KAC). These packages, including the fiberboard assembly within each package, are an integral part of the safety basis for the facility. As such, the continued integrity of the packages must be assured for the duration of storage. Drugstore beetles have been confirmed in three 9975 shipping packages -2 at Hanford and 1 in KAC. SRNL was requested by K-Area personnel to explore the possibility of acoustic detection of beetle-infested packages without opening the packages.

The results of two rounds of testing are presented. The first tests were performed by the vendor using only the hand-held instrument's indications and real-time operator analysis of the audio signal content. The second tests included hands-free positioning of the instrument probe and post-collection analysis of the recorded audio signal content including audio background comparisons.

\subsection{Feasibility Testing}

\subsection{Demonstration and Testing by Instrument Vendor}

On July 12, 2012, Mr. John Rodgers of Acoustic Emission Consulting, Inc (AEC) demonstrated the ability of the AEC Model AED-2010 portable acoustic emission instrument and SP-1L probe set to detect the presence of drugstore beetles in a 9975 packaging (package without nuclear material) (See Figure 2-1). This system is sold commercially as a portable termite and insect pest detection kit and has a proven track record in detecting insect infestations in a variety of materials including wooden structures, trees, plants and soil. The instrument is a product developed by AEC in collaboration with the USDA Agricultural Research Service. The insect detection kit consists of a handheld control console, a connected emissions probe with optional tips to provide acoustic coupling to the inspected material, and headphones to listen directly to the amplified / processed signal (See Figure 2-2). Noises generated typically during insect feeding activity are detected by the system and presented as audible sharp pops and crackles in the instrument's headphone audio output for the operator. The instrument also analyzes the signal for magnitudes that exceed a preset threshold value. A light on the instrument illuminates when the signal exceeds the threshold and cumulative totals of counts and hits are displayed.

Two 9975 packagings were staged in Building 723-15A and used in this demonstration packaging 9975-03996 was known to contain live drugstore beetles, and packaging 9975-01818 was known to be free of infestation. 
Several configurations were tested during this demonstration. A drum dolly was used to lay the packaging on its side, providing access to the drum bottom, and sides (See Figure 2-3 and Figure 2-4). The instrument probe was handheld in tight contact with the drum surface, on both the bottom, and along the lower portion of the side where the fiberboard was in contact with the drum. This setup was used for both packagings. In addition, the infested packaging was opened, and a $1 / 16$ inch drill bit was inserted into the fiberboard in several locations. The probe was acoustically coupled to the drill bit, providing a stronger signal without the attenuation due to the drum wall (See Figure 2-5, Figure 2-6 and Figure 2-7). (Steps were taken to contain the beetles during this activity.)

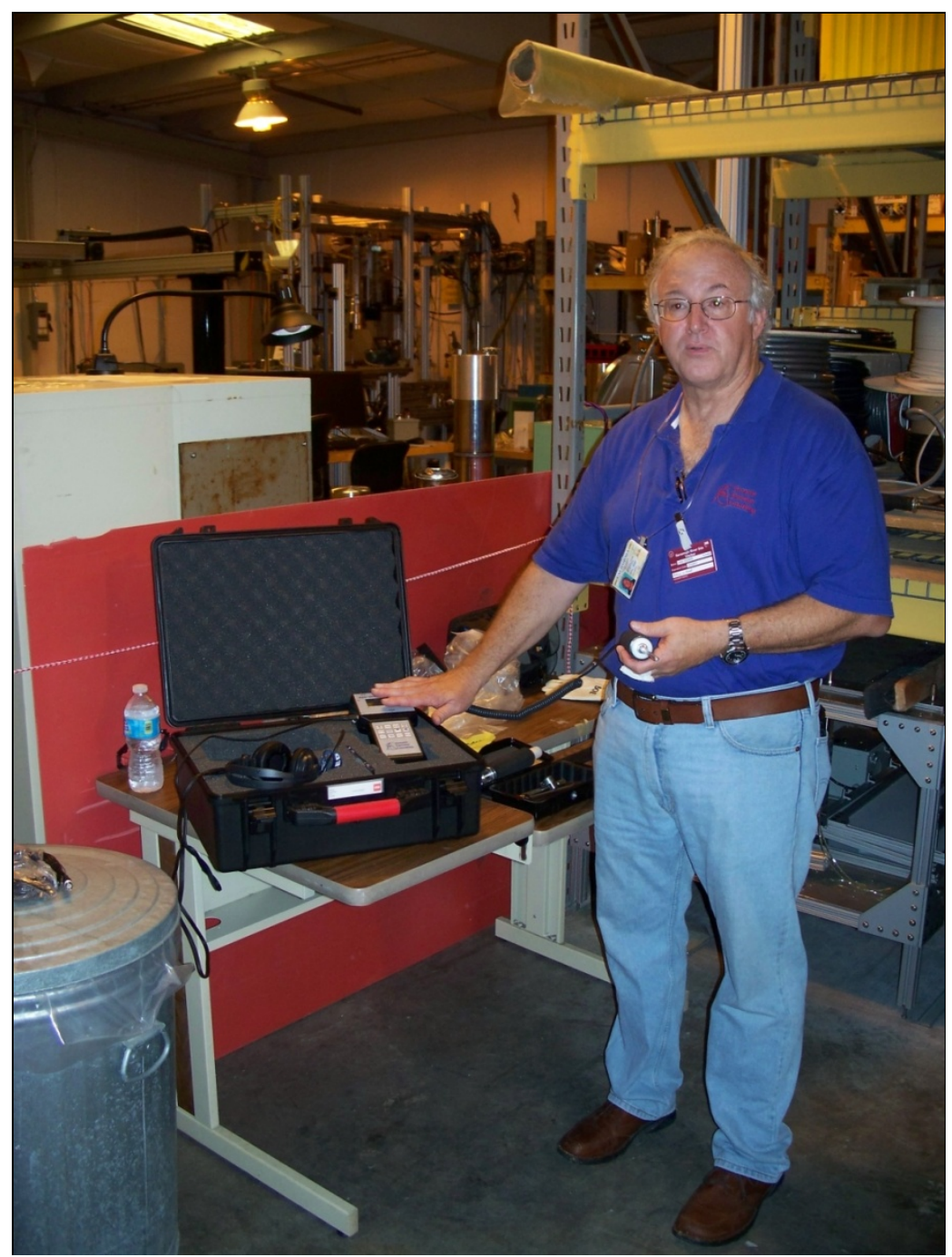

Figure 2-1. Mr. John Rodgers of Acoustic Emission Consulting with Portable Insect Detection Kit

In general for this round of experiments, the detected signal magnitude did not exceed the threshold, but an audible signal was discernible by the operator. In order for the beetles to be detected, the probe had to be in acoustical contact with the packaging drum. A stronger signal is received from regions of the drum which are in direct contact with the fiberboard, specifically on the bottom of the drum or along the lower portion of the sidewall when the packaging was laid on 
its side. This is due to the better acoustical coupling of the insect noise from the fiberboard to the drum wall where there is no air gap separation between the materials.

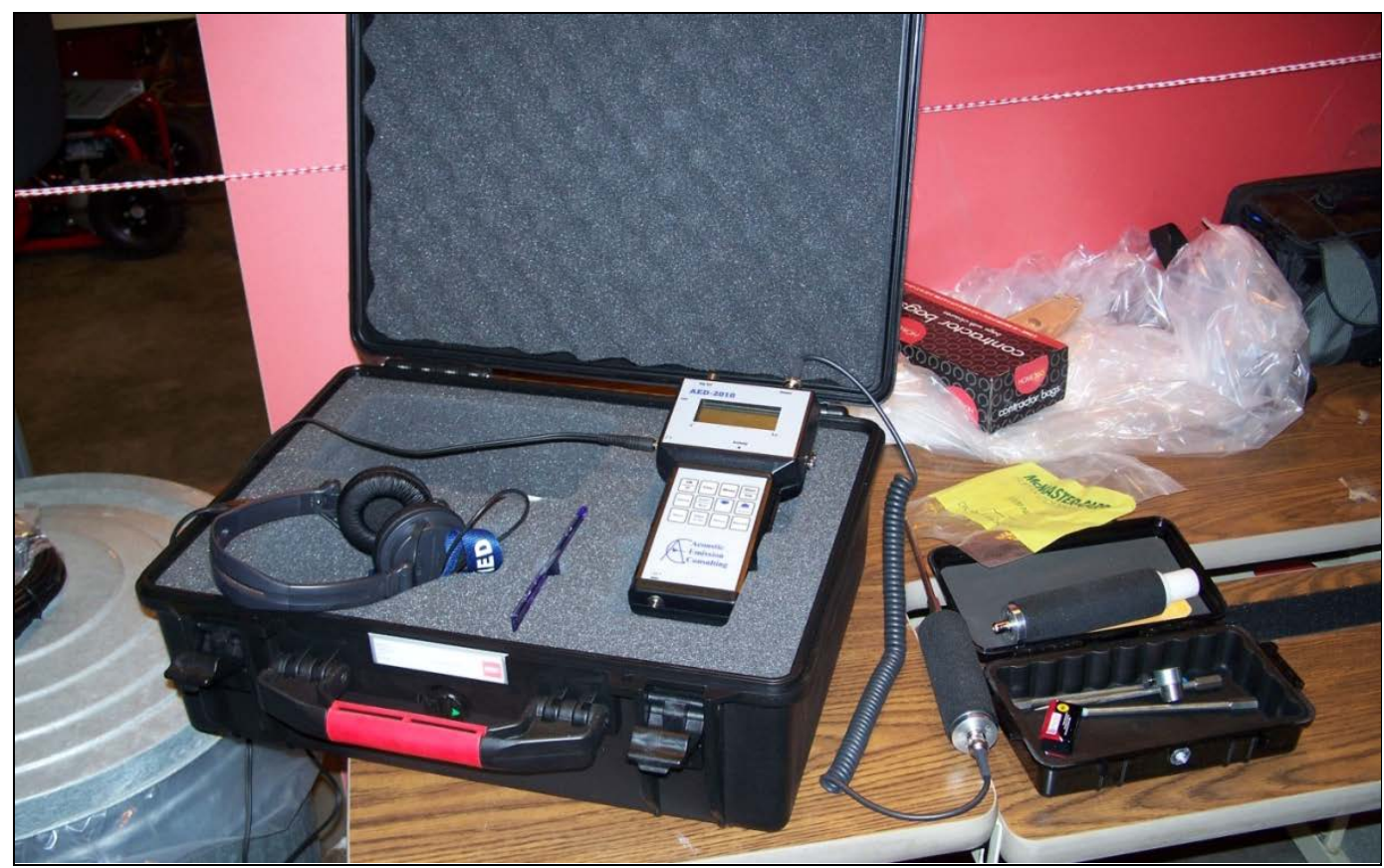

Figure 2-2. Acoustic Emission Consulting Portable Insect Detection Kit

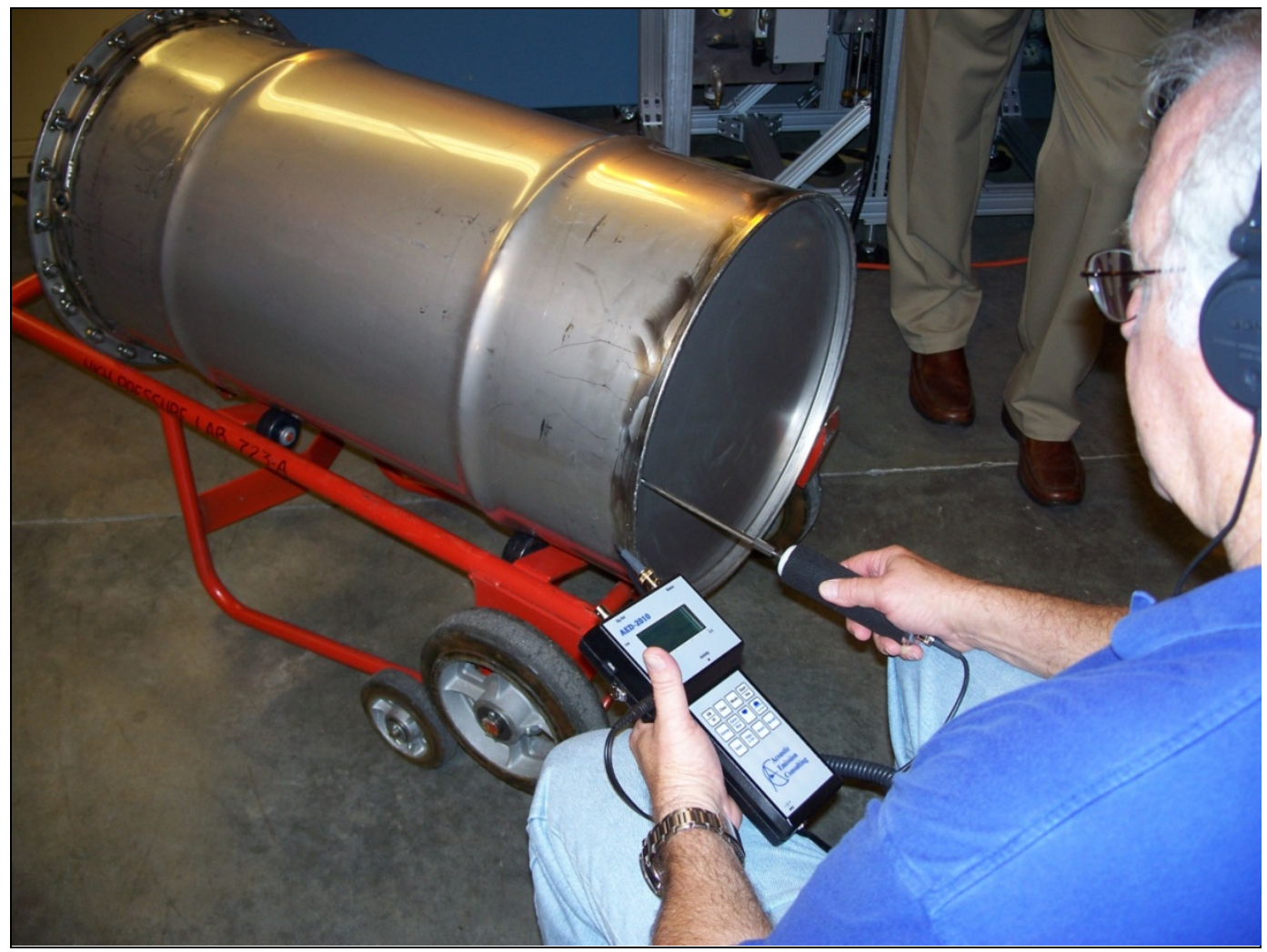

Figure 2-3. Acoustic Emission Consulting AED-2010L Instrument and SP-1L Probe 


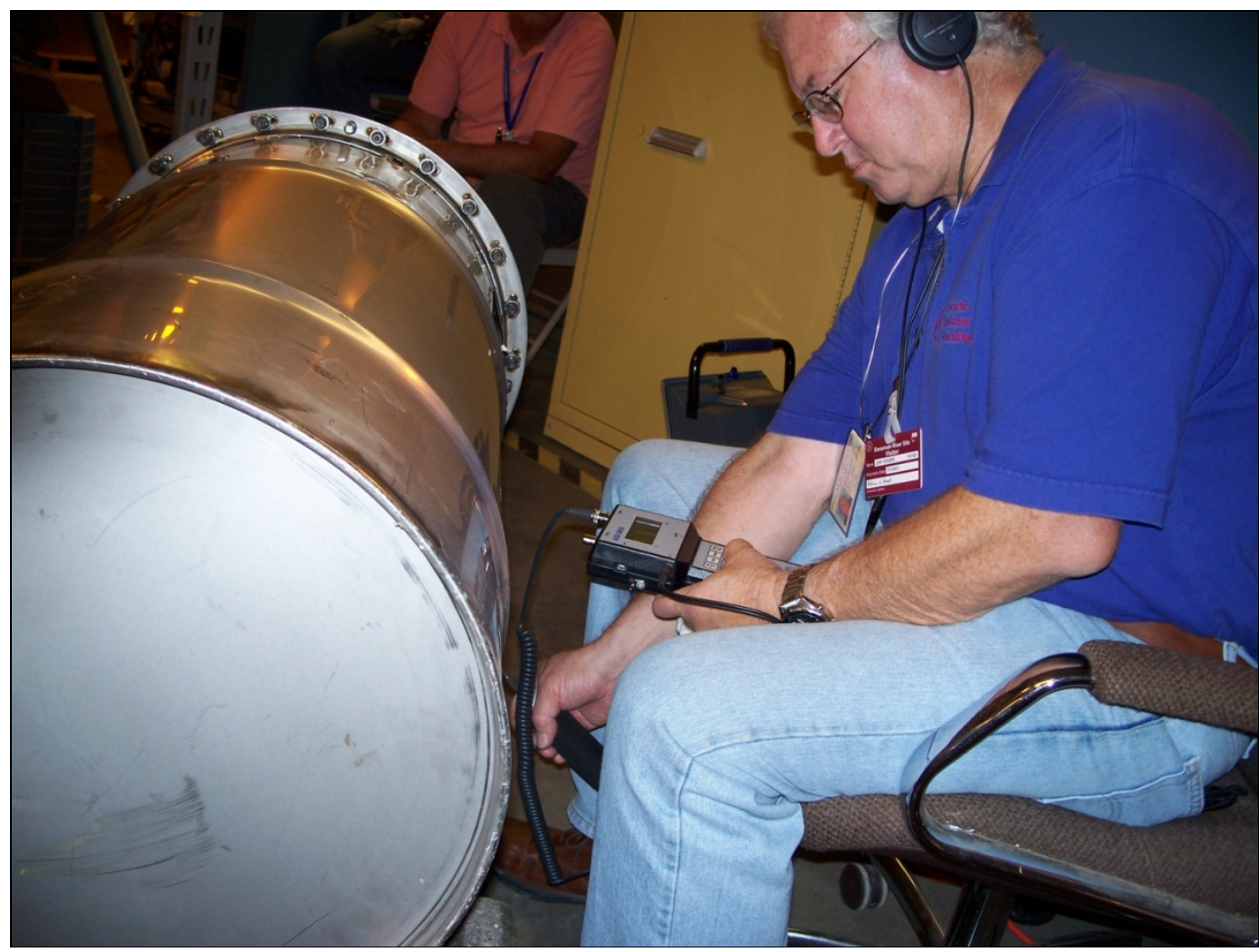

Figure 2-4. Inspection on Sidewall Surface

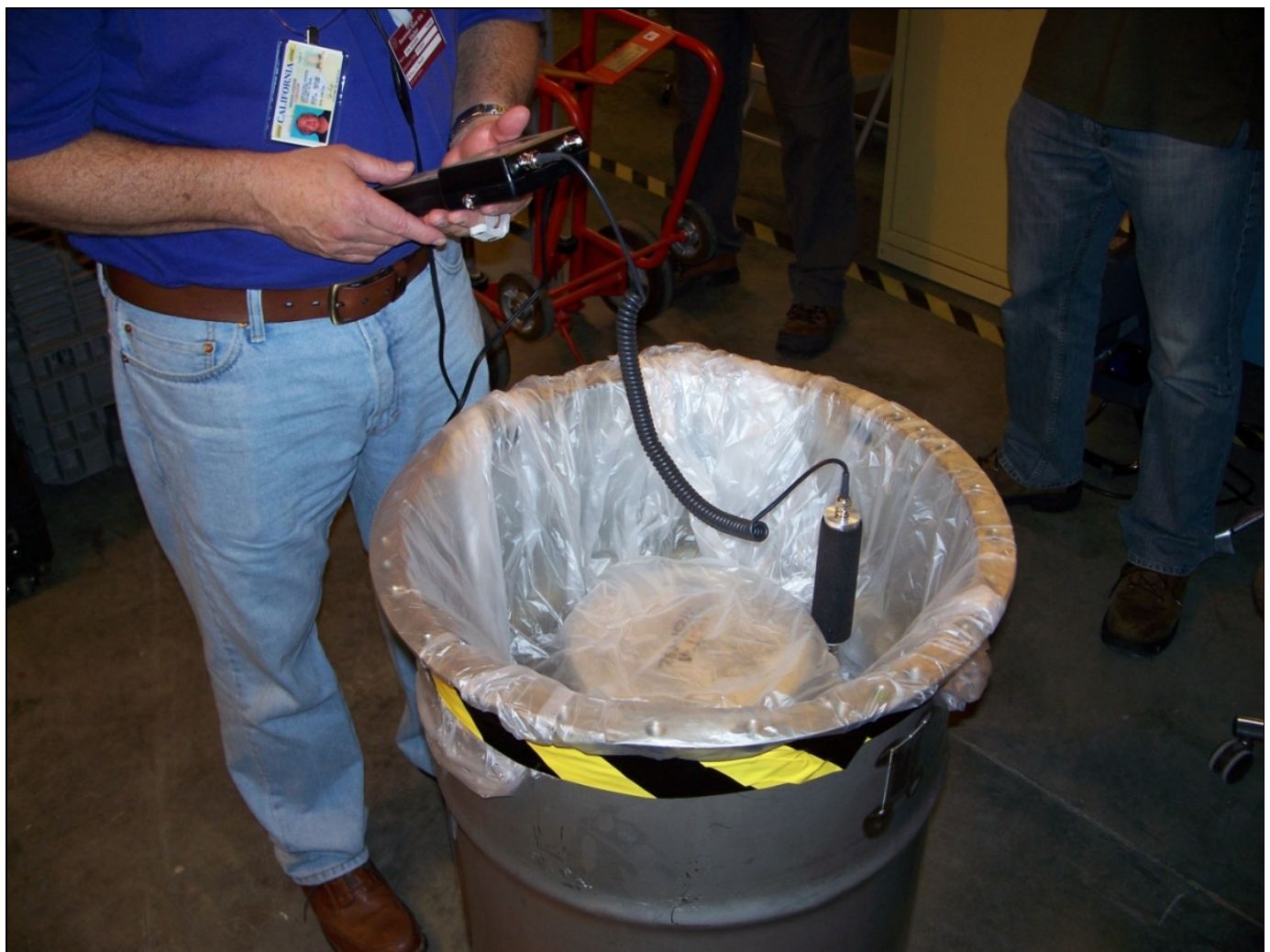

Figure 2-5. Probe Coupled to Celotex ${ }^{\mathrm{TM}}$ Using Drill Bit Adapter 


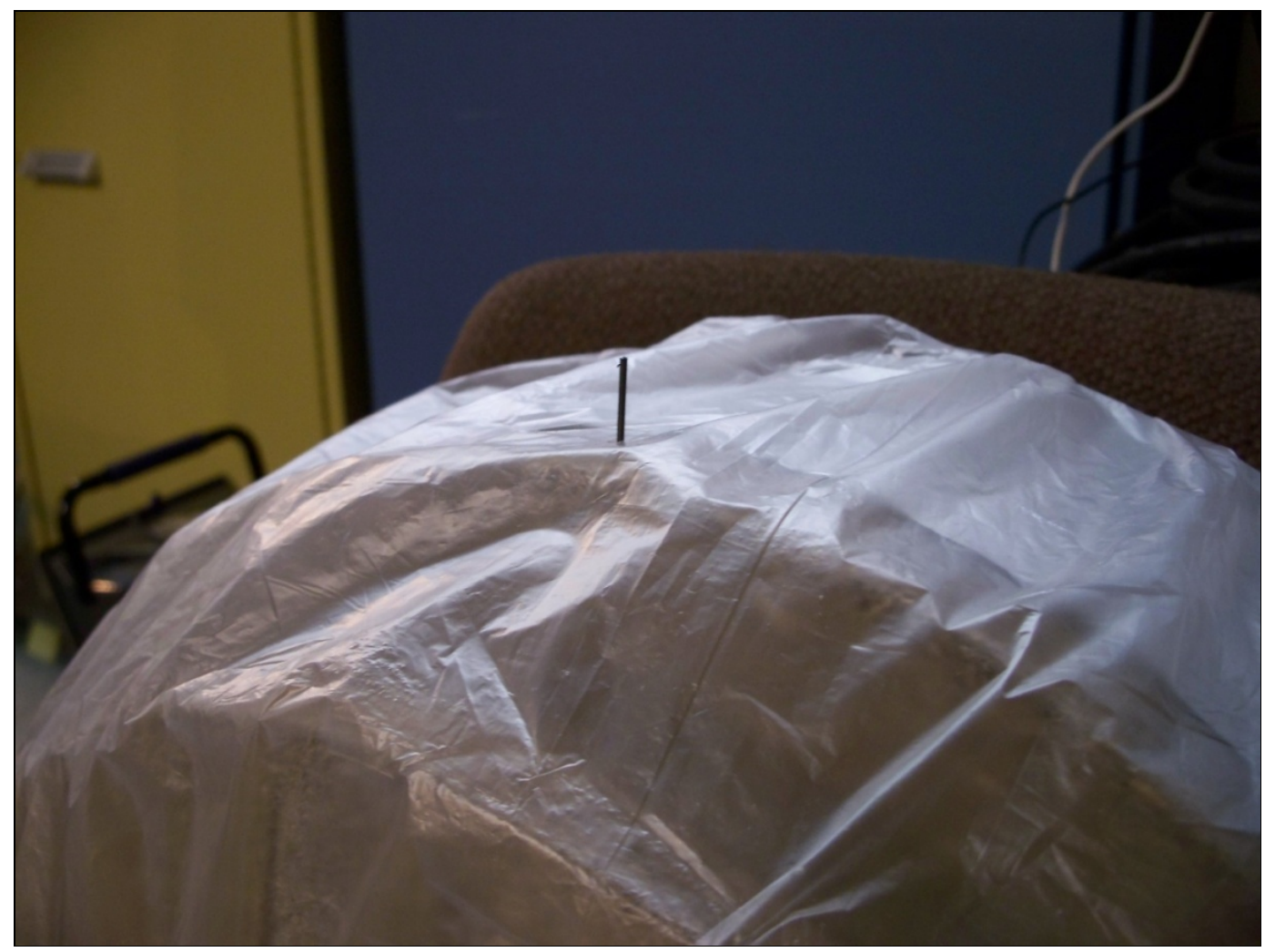

Figure 2-6. Drill Bit Inserted into Celotex ${ }^{\mathrm{TM}}$ in Top Cap

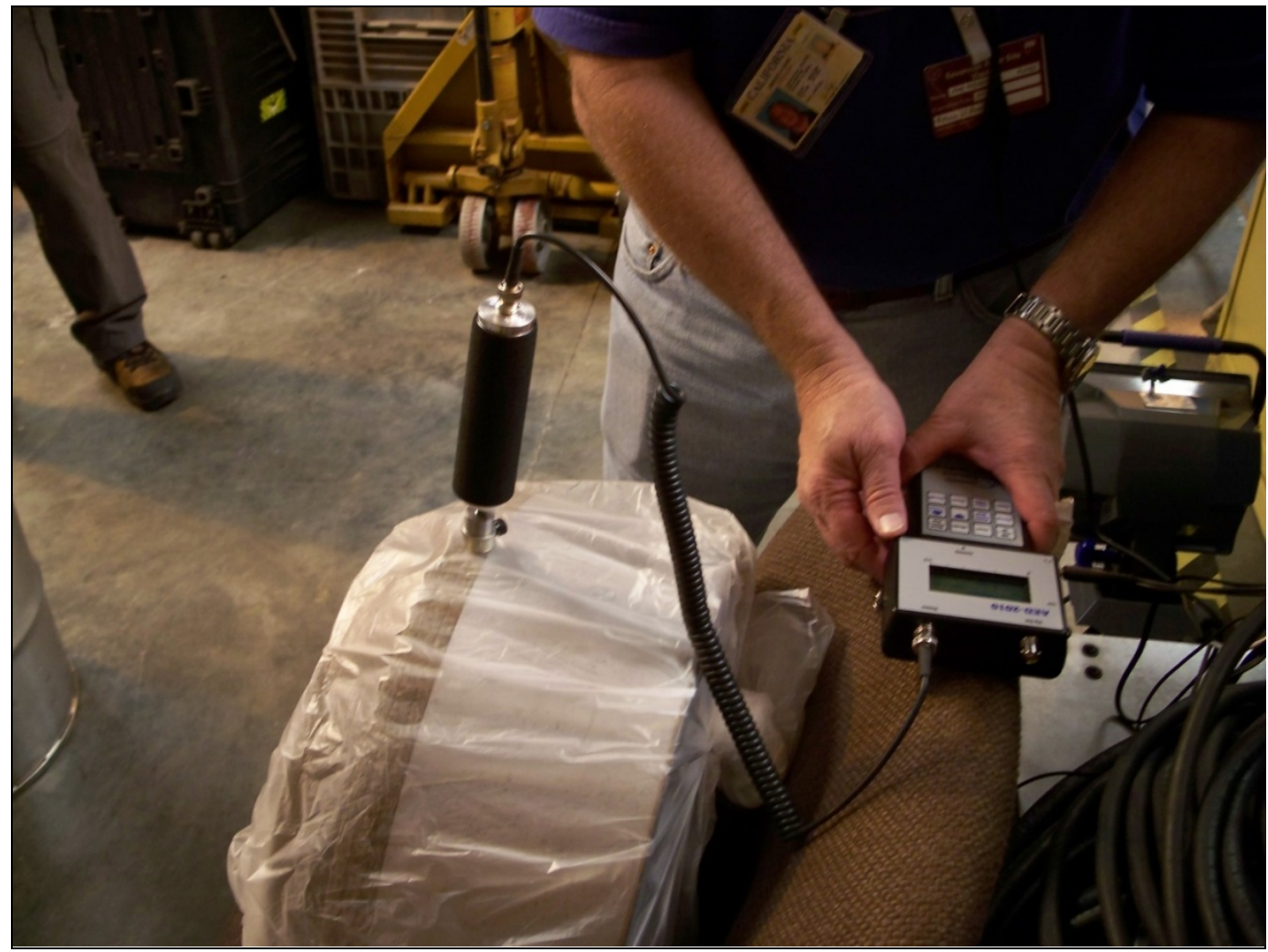

Figure 2-7. Probe Coupled to Celotex ${ }^{\mathrm{TM}}$ in Top Cap Using Drill Bit Adapter 


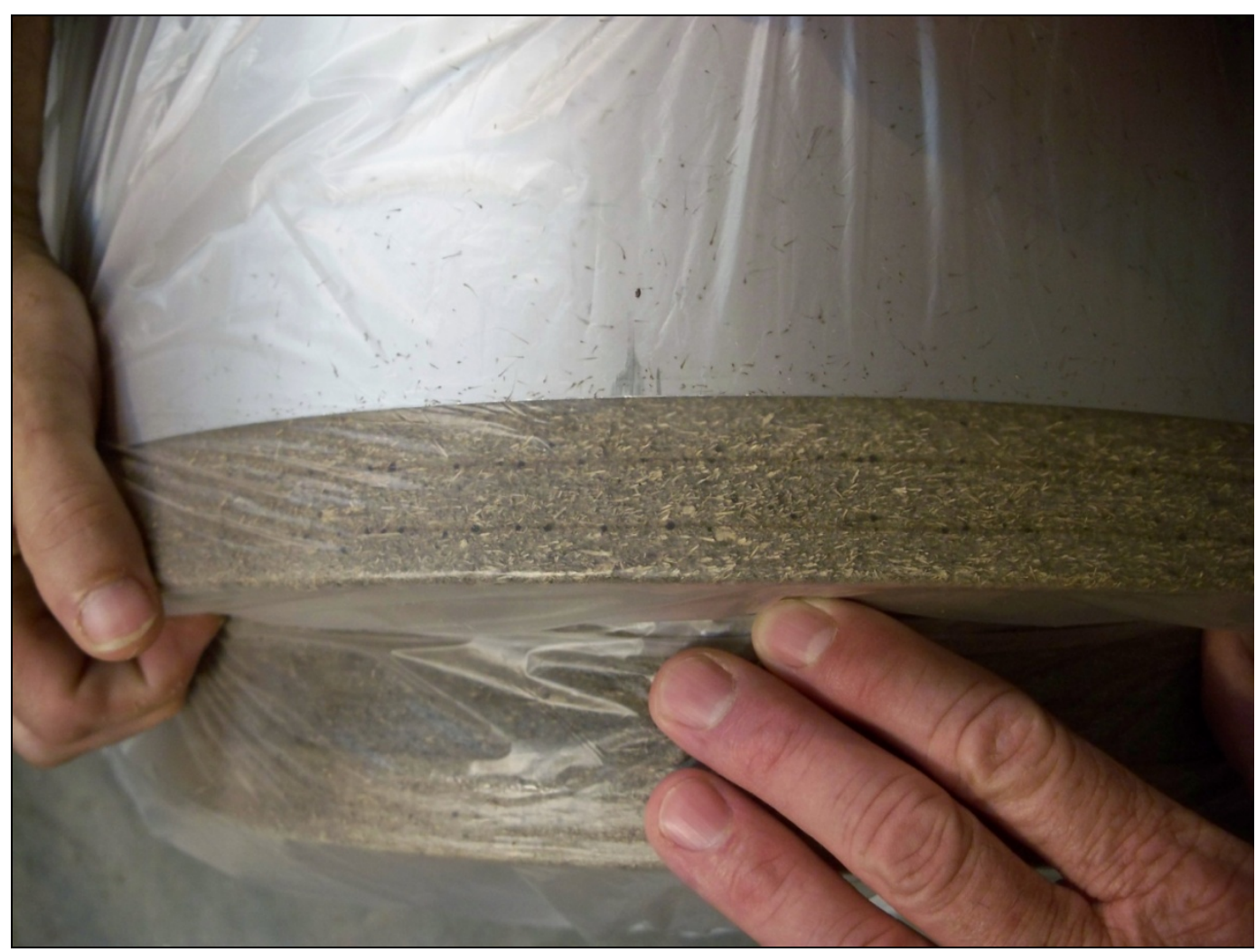

Figure 2-8. Bore Hole Evidence of Beetles

\subsection{Additional Testing and Data Collection}

Additional testing was performed on these same packagings integrating a laptop computer for recording and signal processing, an ambient microphone for background noise detection and monitoring and an audio mixer for signal conditioning and frequency filtering (See Figure 2-9 and Figure 2-10). A microphone stand was used to provide hands-free placement of the AEC model SP-1L detector probe in contact with the drum surface approximately 4 inches from the bottom of the drum (See Figure 2-11 to Figure 2-14). The laptop computer was also used to provide additional flexibility in the configuration of the AED-2010L instrument settings by using the Acoustic Emission Detector software application (version 3.2.0) interfaced to the instrument via USB cable.

Audacity version 2.0.1 digital audio editing software was used to record and analyze the audio recordings (See Figure 2-15). The list of recordings by date, time and test conditions is presented in 
Table 2-1. These recordings are accessible as Audacity project files, one project file for each day of testing. Audacity provides the ability to export the recordings in several audio formats including MP3. Stereo (2-track) recordings were created with the AED-2010L instrument audio output recorded on the left track and the background microphone audio recorded on the right track. This method allows comparison of the instrument audio with the background signal to determine if specific sounds originated outside of the packaging under test and were acoustically coupled through the outer steel drum wall. The best recorded results were obtained by reducing the room background noise as much as possible, mainly by turning off the building ventilation system during data collection intervals. Ventilation system noise was fairly significant in this open area storage building structure and created a broad spectrum background increase in both signal tracks.

For these tests the packagings were always oriented upright on the floor and the detector probe was placed on the drum sidewall approximately 4 inches from the bottom of the drum. The instrument settings were configured as follows using the Acoustic Emission Detector software application:

$$
\begin{aligned}
& \text { Mode }=\text { Hits } \\
& \text { Threshold }(\mathrm{v})=1.00 \\
& \text { Threshold }(\mathrm{dB})=20 \\
& \text { Variable Gain }=40 \\
& \text { Fixed Gain }=20 \\
& \text { Preamp Gain }=40 \\
& \text { Total Gain }=100
\end{aligned}
$$

The automated instrument "hit" detection mode was still not useful as an indicator of beetle feeding noise even with the increased system gain made possible through use of the Acoustic Emission Detector software instrument interface. Sharp cracks or pops could be identified, however, in the audio recordings of the infested packaging. These distinct sounds are produced by the instrument as an audible indicator for an inspector normally monitoring with headphones and are generated when the detector receives a certain magnitude signal at an ultrasonic frequency (above the normal range of human hearing). By analyzing the recorded background signal, it was possible to determine whether these sounds originated from inside the packaging or from background noises in the surroundings. Two recordings were captured by first processing the signals through the audio mixer's multi-band graphic equalizer to apply a band pass filter centered at $1 \mathrm{kHz}$. Frequencies outside of the $1 \mathrm{kHz}$ centered band were attenuated (See Figure 2-16). The raw stereo audio track recordings were also post-processed through various high pass, low pass and notch frequency filters to aid in isolating the signal content of interest from the background noise. From the results of these signal processing trials, it can be concluded that a suitable processing algorithm could be fashioned to improve the automated detection scheme enabling the reduction of operator required actions during an inspection. 


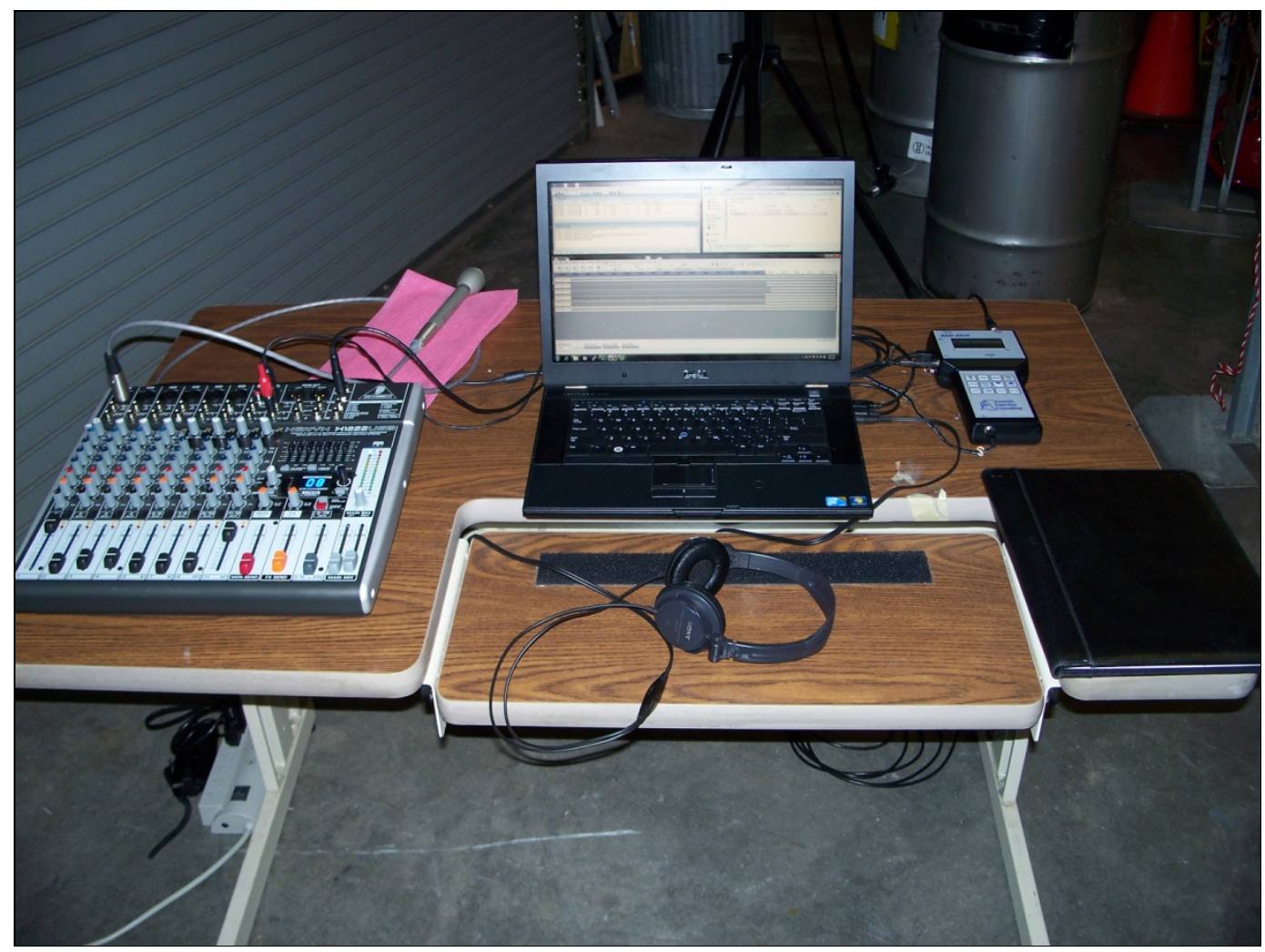

Figure 2-9. Data Collection Instrumentation for Recorded Measurements

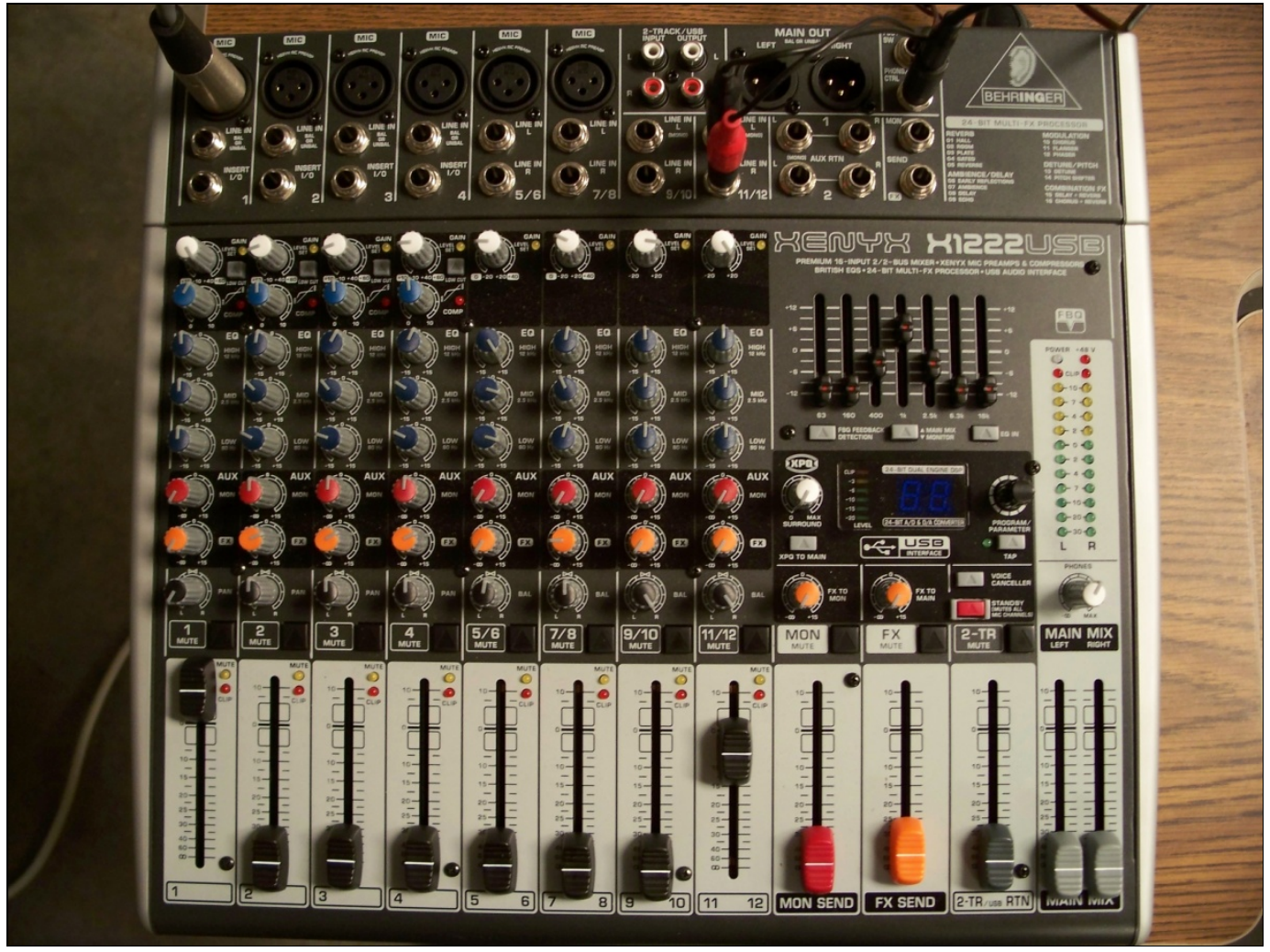

Figure 2-10. Audio Mixing Console used for Signal Conditioning 


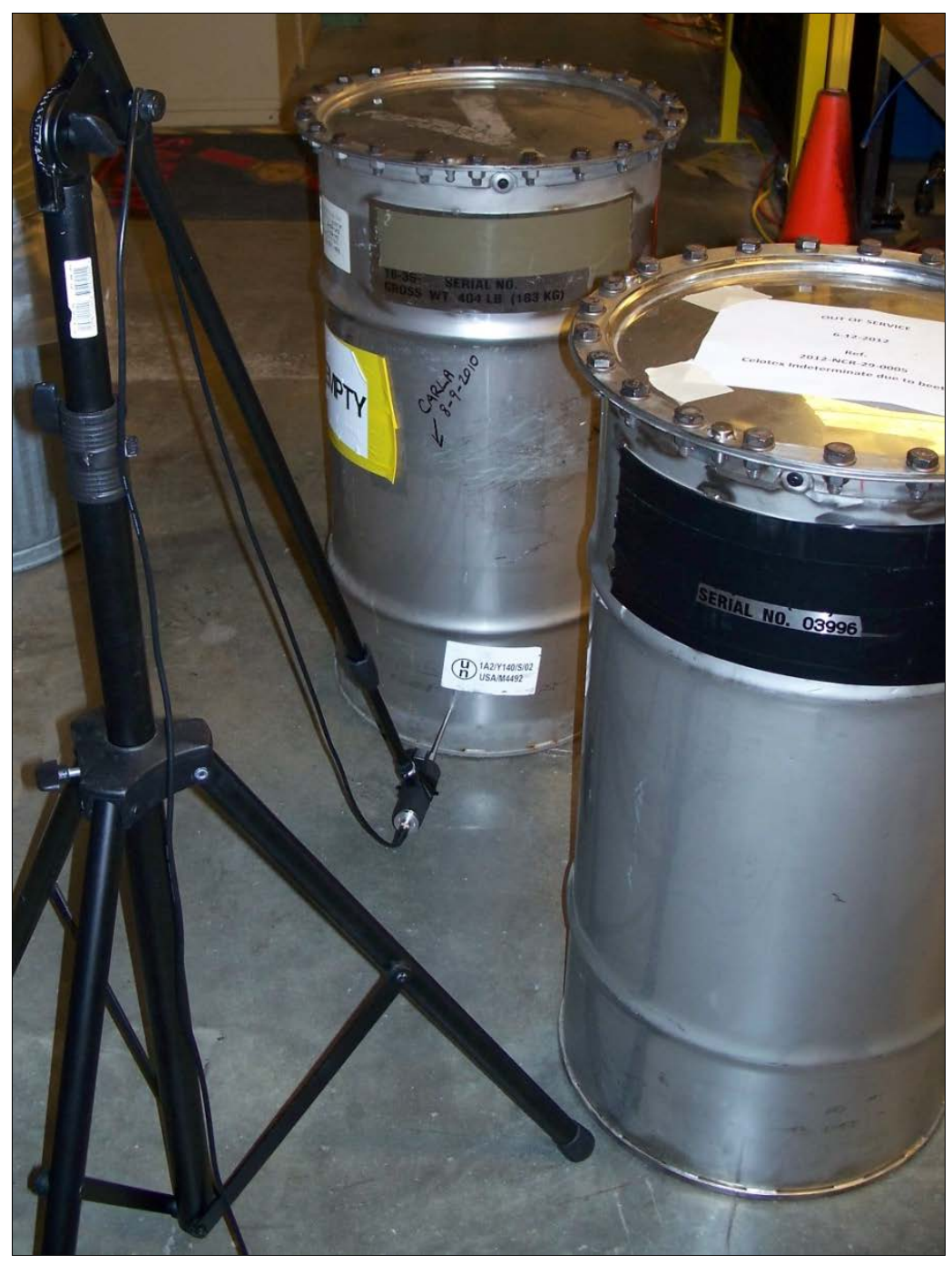

Figure 2-11. Hands-free Positioning of Detector Probe with Microphone Boom Stand 


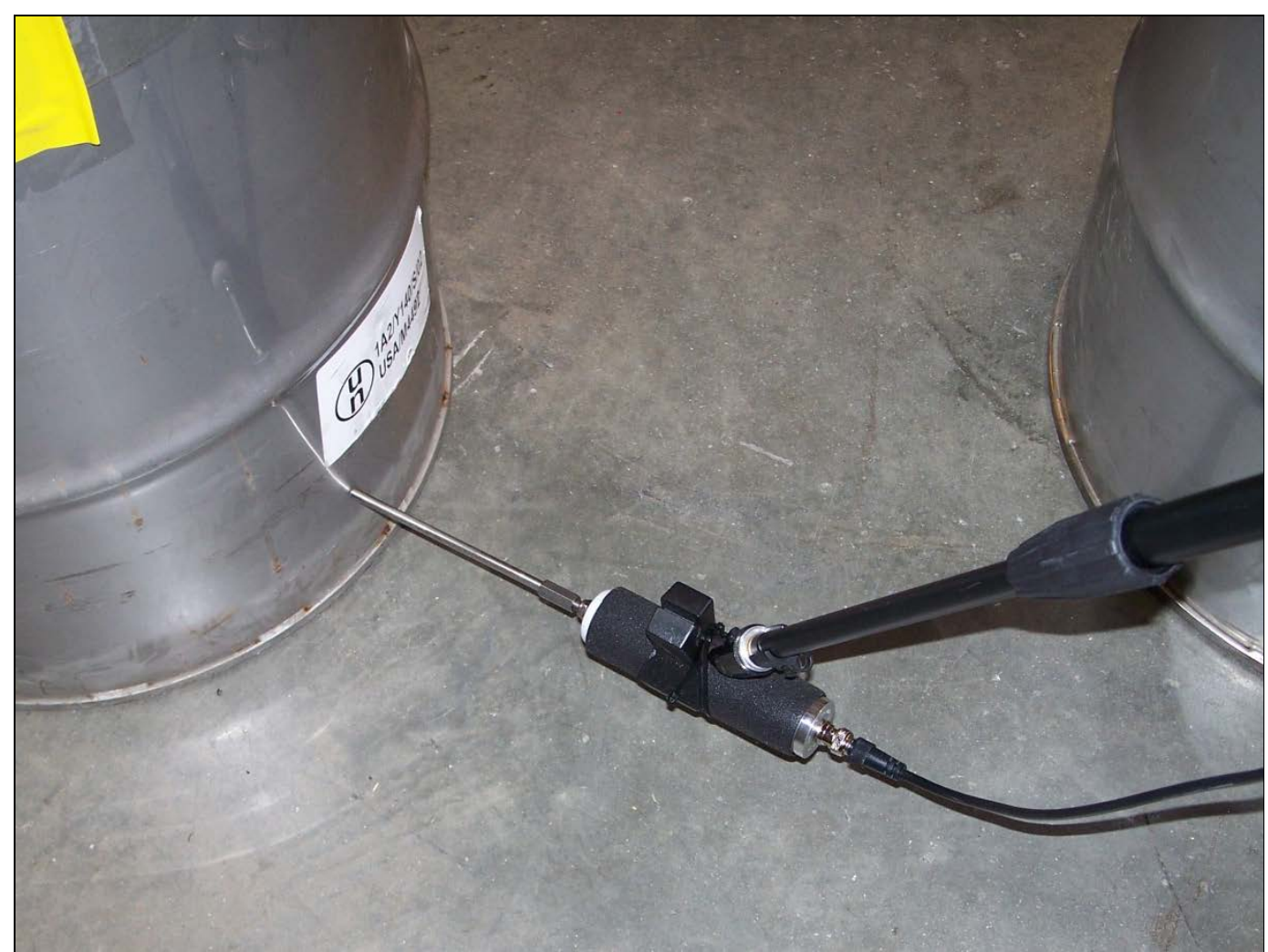

Figure 2-12. Placement at Approximately 4 Inches from Bottom of Packaging

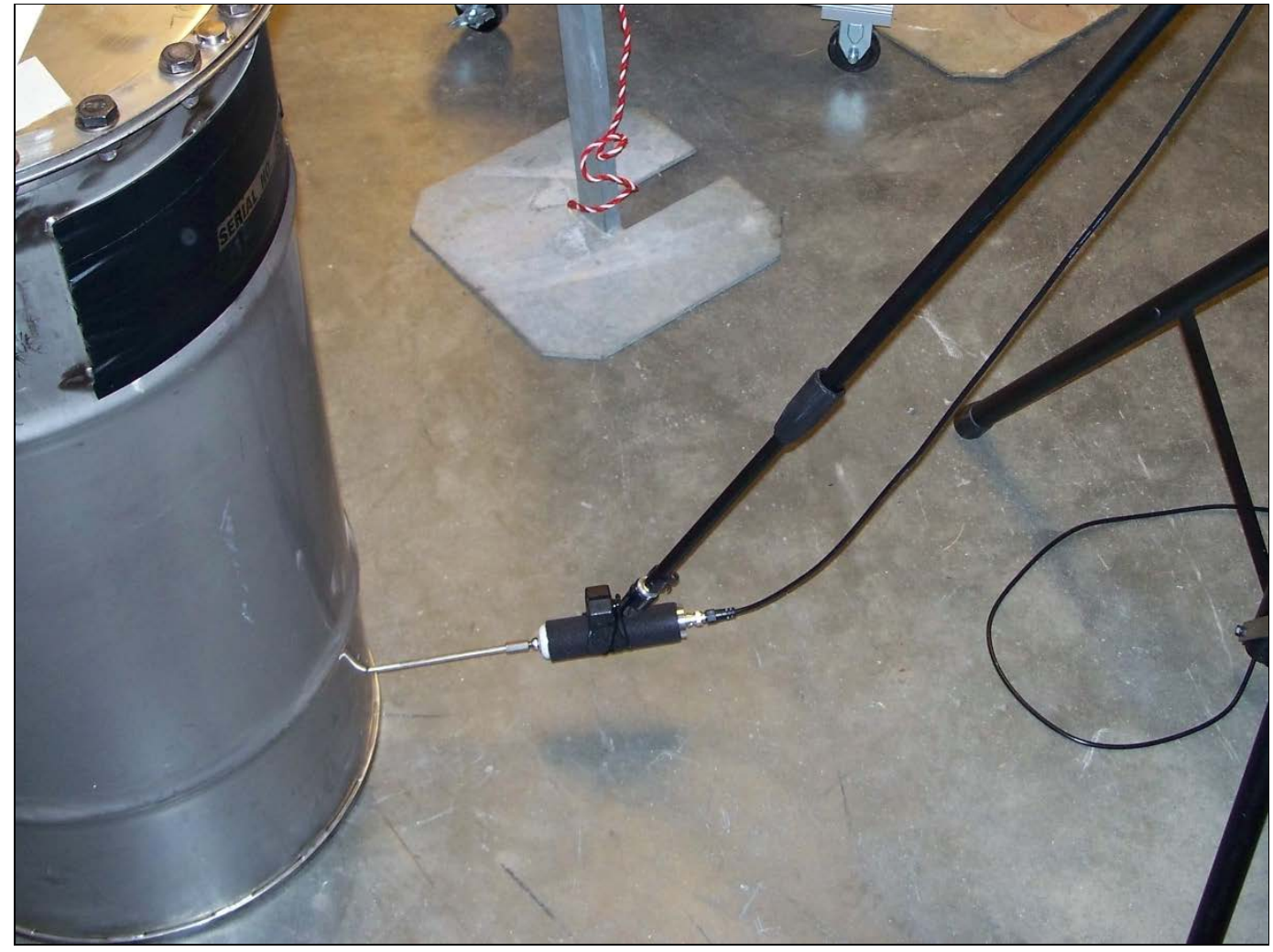

Figure 2-13. Side View of Probe Placement 


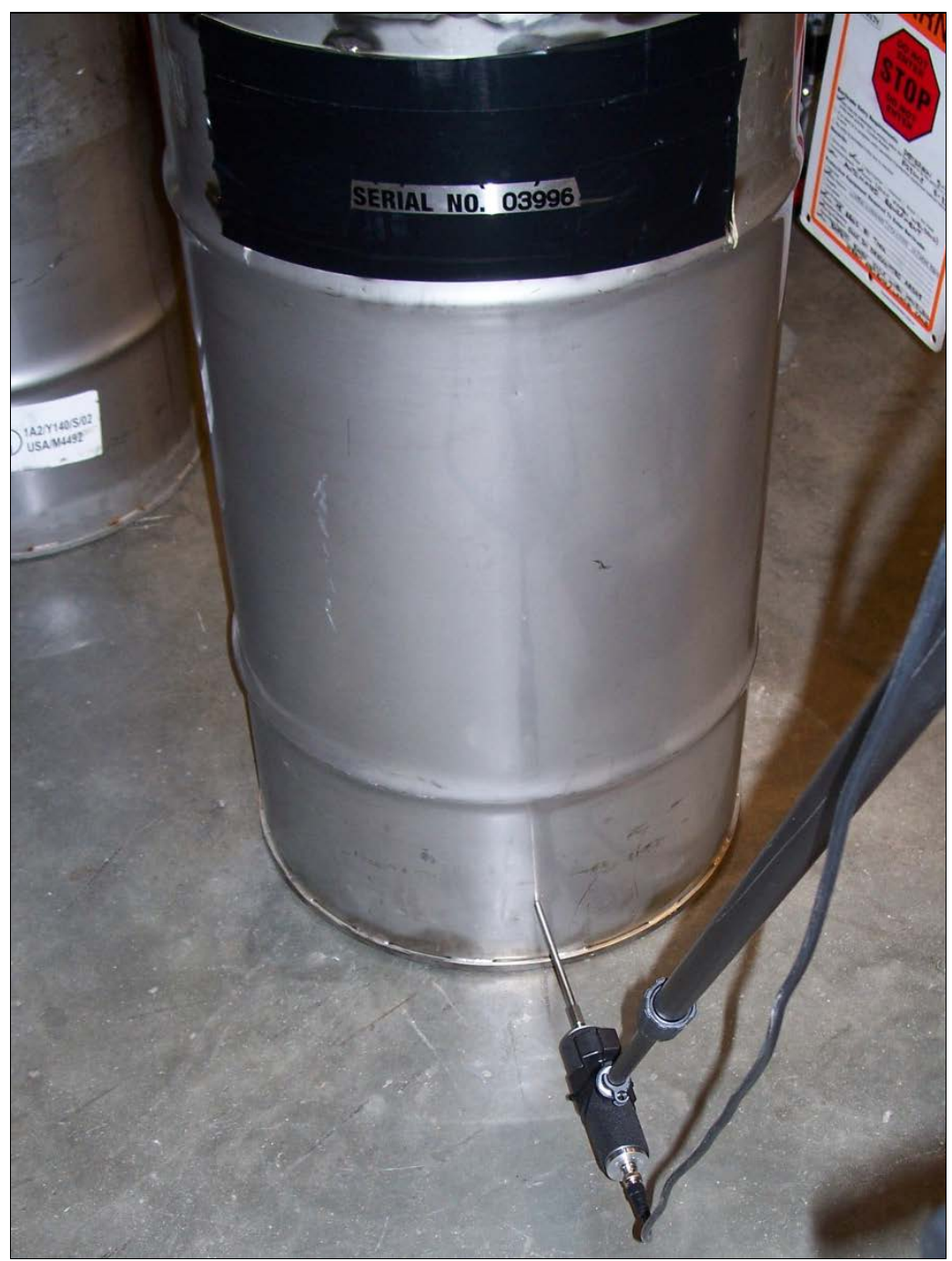

Figure 2-14. Rear View of Probe Placement 


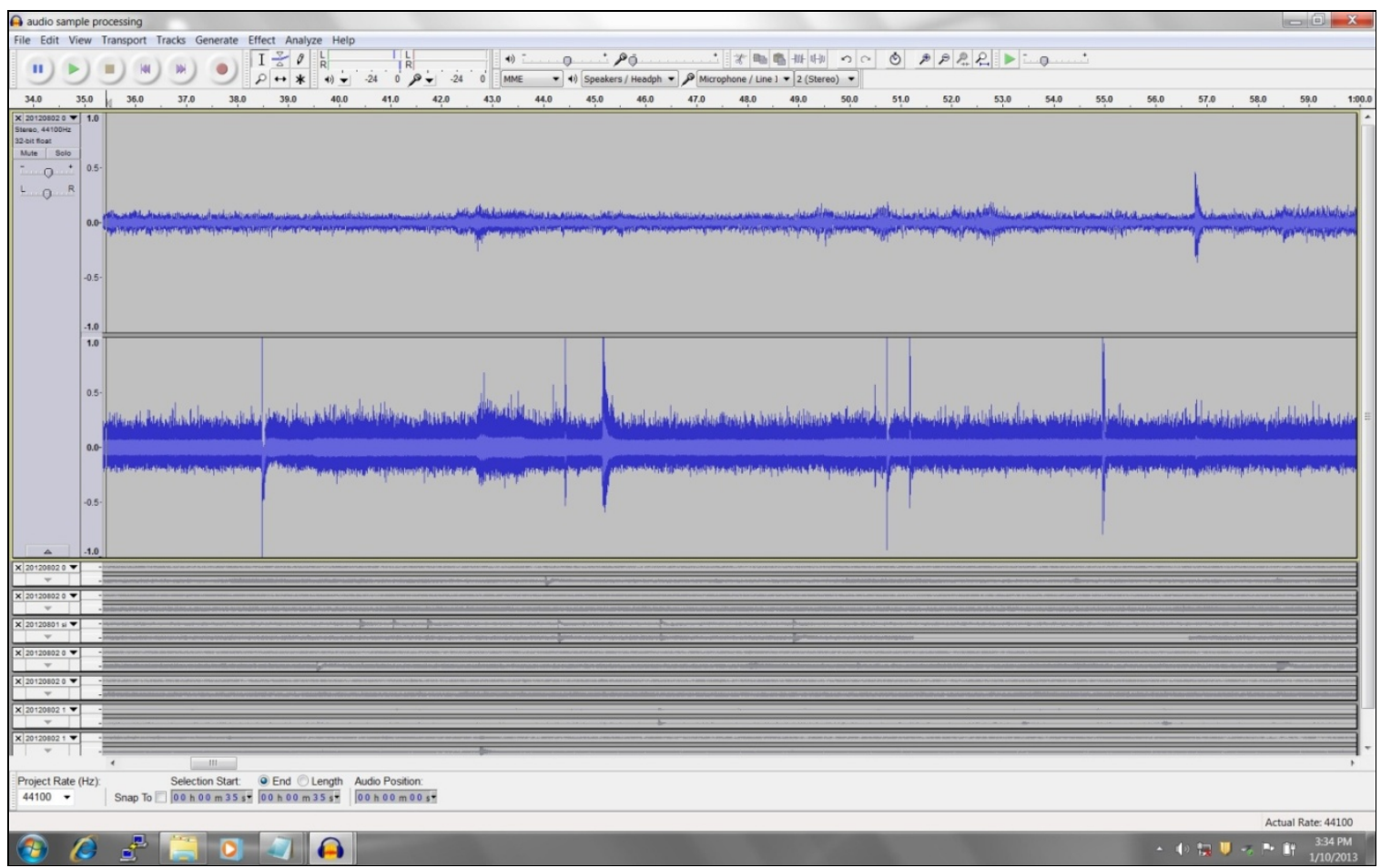

Figure 2-15. Audacity Digital Audio Editor Software Screenshot

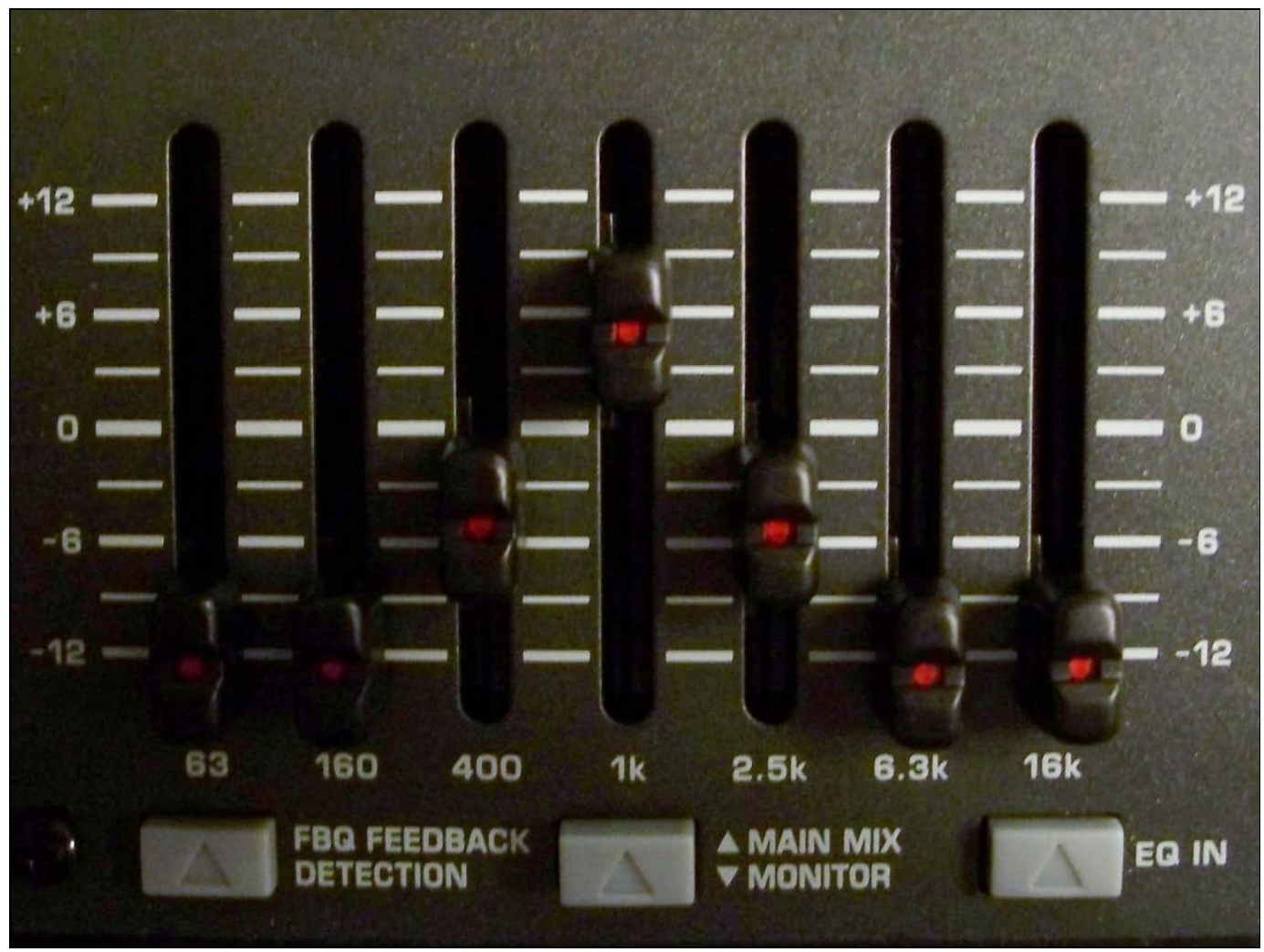

Figure 2-16. Spectrum Filter Applied on 2 Recorded Tracks 
Table 2-1. Catalog of Recordings

\begin{tabular}{|c|c|c|c|}
\hline Packaging S/N & Date & Time & "Comments/Events \\
\hline \multirow[t]{5}{*}{03996} & $8 / 1 / 2012$ & 9:23:22 AM & $\begin{array}{l}\text { 1st run, probe contacting side approx } 4 \\
\text { inches from bottom. Drum upright. }\end{array}$ \\
\hline & $8 / 1 / 2012$ & 9:23:22 AM & Sampling session started. \\
\hline & $8 / 1 / 2012$ & 9:23:22 AM & $\begin{array}{l}\text { Mode }=\text { Hits Thresh }(\mathrm{v})=1.00 \text { Thresh }(\mathrm{dB})=20 \\
\text { Var gain }=40 \text { Fixed gain=20 Preamp gain }=40 \\
\text { Total gain }=100\end{array}$ \\
\hline & $8 / 1 / 2012$ & 9:23:22 AM & Sample processing $=$ accumulate and store \\
\hline & $8 / 1 / 2012$ & 9:29:45 AM & Sampling session terminated. \\
\hline \multirow[t]{5}{*}{01818} & $8 / 1 / 2012$ & 10:39:39 AM & Sampling session started. \\
\hline & 8/1/2012 & 10:39:39 AM & $\begin{array}{l}\text { 1st run, probe contacting side approx } 4 \\
\text { inches from bottom. Drum upright. }\end{array}$ \\
\hline & $8 / 1 / 2012$ & 10:39:39 AM & $\begin{array}{l}\text { Mode }=\text { Hits Thresh }(\mathrm{v})=1.00 \text { Thresh }(\mathrm{dB})=20 \\
\text { Var gain }=40 \text { Fixed gain }=20 \text { Preamp gain }=40 \\
\text { Total gain }=100\end{array}$ \\
\hline & $8 / 1 / 2012$ & 10:39:39 AM & Sample processing= accumulate and store \\
\hline & $8 / 1 / 2012$ & 10:45:53 AM & Sampling session terminated. \\
\hline \multirow[t]{5}{*}{01818} & $8 / 1 / 2012$ & 11:23:02 AM & $\begin{array}{l}\text { 2nd run, probe contacting side approx } 4 \\
\text { inches from bottom. Drum upright. } \\
\text { Weedeater running, forklift,... }\end{array}$ \\
\hline & $8 / 1 / 2012$ & 11:23:02 AM & Sampling session started. \\
\hline & $8 / 1 / 2012$ & 11:23:02 AM & $\begin{array}{l}\text { Mode }=\text { Hits Thresh }(\mathrm{v})=1.00 \text { Thresh }(\mathrm{dB})=20 \\
\text { Var gain }=40 \text { Fixed gain=20 Preamp gain }=40 \\
\text { Total gain }=100\end{array}$ \\
\hline & $8 / 1 / 2012$ & 11:23:02 AM & Sample processing= accumulate and store \\
\hline & $8 / 1 / 2012$ & 11:34:30 AM & Sampling session terminated. \\
\hline \multirow[t]{5}{*}{01818} & $8 / 1 / 2012$ & 1:47:05 PM & $\begin{array}{l}\text { 3rd run, probe contacting side approx } 4 \\
\text { inches from bottom. Drum upright. AC } \\
\text { running throughout. }\end{array}$ \\
\hline & $8 / 1 / 2012$ & 1:47:05 PM & Sampling session started. \\
\hline & 8/1/2012 & 1:47:05 PM & $\begin{array}{l}\text { Mode }=\text { Hits Thresh }(\mathrm{v})=1.00 \text { Thresh }(\mathrm{dB})=20 \\
\text { Var gain }=40 \text { Fixed gain=20 Preamp gain }=40 \\
\text { Total gain }=100\end{array}$ \\
\hline & $8 / 1 / 2012$ & 1:47:05 PM & Sample processing $=$ accumulate and store \\
\hline & $8 / 1 / 2012$ & 1:54:34 PM & Sampling session terminated. \\
\hline \multirow[t]{5}{*}{03996} & 8/1/2012 & 2:22:59 PM & $\begin{array}{l}\text { 2nd run, probe contacting side approx } 4 \\
\text { inches from bottom. Drum upright. truck } \\
\text { passes by at end. }\end{array}$ \\
\hline & $8 / 1 / 2012$ & 2:22:59 PM & Sampling session started. \\
\hline & 8/1/2012 & 2:22:59 PM & $\begin{array}{l}\text { Mode }=\text { Hits Thresh }(\mathrm{v})=1.00 \text { Thresh }(\mathrm{dB})=20 \\
\text { Var gain }=40 \text { Fixed gain=20 Preamp gain }=40 \\
\text { Total gain=100 }\end{array}$ \\
\hline & $8 / 1 / 2012$ & 2:22:59 PM & Sample processing $=$ accumulate and store \\
\hline & $8 / 1 / 2012$ & 2:29:16 PM & Sampling session terminated. \\
\hline \multirow[t]{5}{*}{03996} & $8 / 1 / 2012$ & 2:41:53 PM & $\begin{array}{l}\text { 3rd run, probe contacting side approx } 4 \\
\text { inches from bottom. Drum upright. }\end{array}$ \\
\hline & $8 / 1 / 2012$ & 2:41:53 PM & Sampling session started. \\
\hline & $8 / 1 / 2012$ & 2:41:53 PM & $\begin{array}{l}\text { Mode }=\text { Hits Thresh }(\mathrm{v})=1.00 \text { Thresh }(\mathrm{dB})=20 \\
\text { Var gain }=40 \text { Fixed gain=20 Preamp gain }=40 \\
\text { Total gain=100 }\end{array}$ \\
\hline & $8 / 1 / 2012$ & 2:41:53 PM & Sample processing= accumulate and store \\
\hline & $8 / 1 / 2012$ & 2:47:31 PM & Sampling session terminated. \\
\hline
\end{tabular}




\begin{tabular}{|c|c|c|c|}
\hline \multirow[t]{8}{*}{03996} & $8 / 1 / 2012$ & 4:06:44 PM & $\begin{array}{l}\text { 4th run, probe contacting side approx } 4 \\
\text { inches from bottom. Drum upright. AC } \\
\text { turned OFF until end. }\end{array}$ \\
\hline & 8/1/2012 & 4:06:44 PM & Sampling session started. \\
\hline & $8 / 1 / 2012$ & 4:06:44 PM & $\begin{array}{l}\text { Mode }=\text { Hits Thresh }(\mathrm{v})=1.00 \text { Thresh }(\mathrm{dB})=30 \\
\text { Var gain }=30 \text { Fixed gain=20 Preamp gain }=40 \\
\text { Total gain=90 }\end{array}$ \\
\hline & $8 / 1 / 2012$ & 4:06:44 PM & Sample processing= accumulate and store \\
\hline & 8/1/2012 & 4:10:05 PM & Sampling session paused. \\
\hline & $8 / 1 / 2012$ & 4:10:13 PM & $\begin{array}{l}\text { Mode }=\text { Hits Thresh }(\mathrm{v})=1.00 \text { Thresh }(\mathrm{dB})=20 \\
\text { Var gain }=40 \text { Fixed gain=20 Preamp gain }=40 \\
\text { Total gain=100 }\end{array}$ \\
\hline & $8 / 1 / 2012$ & 4:10:36 PM & Sampling session resumed. \\
\hline & $8 / 1 / 2012$ & 4:32:56 PM & Sampling session terminated. \\
\hline \multirow[t]{5}{*}{03996} & $8 / 2 / 2012$ & 8:21:46 AM & $\begin{array}{l}\text { 1st run, probe contacting side approx } 4 \\
\text { inches from bottom. Drum upright. AC OFF } \\
\text { until end. }\end{array}$ \\
\hline & $8 / 2 / 2012$ & 8:21:46 AM & Sampling session started. \\
\hline & $8 / 2 / 2012$ & 8:21:46 AM & $\begin{array}{l}\text { Mode }=\text { Hits Thresh }(\mathrm{v})=1.00 \text { Thresh }(\mathrm{dB})=20 \\
\text { Var gain }=40 \text { Fixed gain=20 Preamp gain }=40 \\
\text { Total gain }=100\end{array}$ \\
\hline & 8/2/2012 & 8:21:46 AM & Sample processing $=$ accumulate and store \\
\hline & $8 / 2 / 2012$ & 8:28:49 AM & Sampling session terminated. \\
\hline \multirow[t]{5}{*}{01818} & 8/2/2012 & 8:37:42 AM & $\begin{array}{l}\text { 1st run, probe contacting side approx } 4 \\
\text { inches from bottom. Drum upright. AC OFF } \\
\text { Entry into bldg at end. }\end{array}$ \\
\hline & $8 / 2 / 2012$ & $8: 37: 42 \mathrm{AM}$ & Sampling session started. \\
\hline & $8 / 2 / 2012$ & 8:37:42 AM & $\begin{array}{l}\text { Mode }=\text { Hits Thresh }(\mathrm{v})=1.00 \text { Thresh }(\mathrm{dB})=20 \\
\text { Var gain }=40 \text { Fixed gain=20 Preamp gain }=40 \\
\text { Total gain }=100\end{array}$ \\
\hline & $8 / 2 / 2012$ & $8: 37: 42$ AM & Sample processing $=$ accumulate and store \\
\hline & 8/2/2012 & 8:42:51 AM & Sampling session terminated. \\
\hline \multirow[t]{5}{*}{01818} & 8/2/2012 & 9:09:55 AM & $\begin{array}{l}\text { 2nd run, probe contacting side approx } 4 \\
\text { inches from bottom. Drum upright. AC OFF } \\
\text { until end. }\end{array}$ \\
\hline & $8 / 2 / 2012$ & 9:09:55 AM & Sampling session started. \\
\hline & 8/2/2012 & 9:09:55 AM & $\begin{array}{l}\text { Mode }=\text { Hits Thresh }(\mathrm{v})=1.00 \text { Thresh }(\mathrm{dB})=20 \\
\text { Var gain }=40 \text { Fixed gain=20 Preamp gain }=40 \\
\text { Total gain }=100\end{array}$ \\
\hline & $8 / 2 / 2012$ & 9:09:55 AM & Sample processing= accumulate and store \\
\hline & $8 / 2 / 2012$ & 9:12:32 AM & Sampling session terminated. \\
\hline \multirow[t]{5}{*}{01818} & 8/2/2012 & 9:23:26 AM & $\begin{array}{l}\text { 3rd run, probe contacting side approx } 4 \\
\text { inches from bottom. Drum upright. AC OFF } \\
\text { until end. }\end{array}$ \\
\hline & $8 / 2 / 2012$ & 9:23:26 AM & Sampling session started. \\
\hline & $8 / 2 / 2012$ & 9:23:26 AM & $\begin{array}{l}\text { Mode }=\text { Hits Thresh }(\mathrm{v})=1.00 \text { Thresh }(\mathrm{dB})=20 \\
\text { Var gain }=40 \text { Fixed gain=20 Preamp gain }=40 \\
\text { Total gain }=100\end{array}$ \\
\hline & $8 / 2 / 2012$ & 9:23:26 AM & Sample processing $=$ accumulate and store \\
\hline & $8 / 2 / 2012$ & 9:27:03 AM & Sampling session terminated. \\
\hline \multirow[t]{2}{*}{01818} & $8 / 2 / 2012$ & 9:41:19 AM & $\begin{array}{l}\text { 4th run, probe contacting side approx } 4 \\
\text { inches from bottom. Drum upright. PA } \\
\text { announcement at 04:10. AC OFF until end. }\end{array}$ \\
\hline & $8 / 2 / 2012$ & 9:41:19 AM & Sampling session started. \\
\hline
\end{tabular}




\begin{tabular}{|c|c|c|c|}
\hline & $8 / 2 / 2012$ & 9:41:19 AM & $\begin{array}{l}\text { Mode }=\text { Hits Thresh }(\mathrm{v})=1.00 \text { Thresh }(\mathrm{dB})=20 \\
\text { Var gain }=40 \text { Fixed gain=20 Preamp gain=40 } \\
\text { Total gain }=100\end{array}$ \\
\hline & 8/2/2012 & 9:41:19 AM & Sample processing = accumulate and store \\
\hline & $8 / 2 / 2012$ & 9:47:23 AM & Sampling session terminated. \\
\hline \multirow[t]{5}{*}{03996} & $8 / 2 / 2012$ & 10:29:44 AM & $\begin{array}{l}\text { 2nd run, probe contacting side approx } 4 \\
\text { inches from bottom. Drum upright. AC OFF. } \\
1 \mathrm{KHz} \text { bandpass applied at mixer. }\end{array}$ \\
\hline & 8/2/2012 & 10:29:44 AM & Sampling session started. \\
\hline & $8 / 2 / 2012$ & 10:29:44 AM & $\begin{array}{l}\text { Mode }=\text { Hits Thresh }(\mathrm{v})=1.00 \text { Thresh }(\mathrm{dB})=20 \\
\text { Var gain }=40 \text { Fixed gain=20 Preamp gain=40 } \\
\text { Total gain=100 }\end{array}$ \\
\hline & $8 / 2 / 2012$ & 10:29:44 AM & Sample processing $=$ accumulate and store \\
\hline & $8 / 2 / 2012$ & 10:40:12 AM & Sampling session terminated. \\
\hline \multirow[t]{5}{*}{01818} & $8 / 2 / 2012$ & 10:59:16 AM & $\begin{array}{l}\text { 5th run, probe contacting side approx } 4 \\
\text { inches from bottom. Drum upright. AC OFF. } \\
1 \mathrm{KHz} \text { bandpass applied at mixer. }\end{array}$ \\
\hline & $8 / 2 / 2012$ & 10:59:16 AM & Sampling session started. \\
\hline & $8 / 2 / 2012$ & 10:59:16 AM & $\begin{array}{l}\text { Mode }=\text { Hits Thresh }(\mathrm{v})=1.00 \text { Thresh }(\mathrm{dB})=20 \\
\text { Var gain }=40 \text { Fixed gain=20 Preamp gain=40 } \\
\text { Total gain=100 }\end{array}$ \\
\hline & 8/2/2012 & 10:59:16 AM & Sample processing = accumulate and store \\
\hline & $8 / 2 / 2012$ & 11:09:47 AM & Sampling session terminated. \\
\hline
\end{tabular}

\subsection{Results and Discussion}

Though these tests were limited to only 1 sample with beetles and 1 sample free of beetles, the technique and instrumentation produced distinguishable results for the two packagings. Audible indications were clearly detectable in real-time during the packaging scans using the headphones supplied with the kit. These indications were even more apparent and confirmable by comparing the sensor audio to the test environment background audio during post-scan analysis. The vendor has confirmed that the sharp cracks or pops in the audio are indicative of insect feeding activity. These indications are clearly distinguishable to the operator from short-duration background noise acoustically coupled into the drum assembly due to differences in frequency content, duration and reverberant "ringing" qualities attributed to the room and drum acoustic characteristics.

Significant benefit was obtained through the use of a hands-free method of probe placement on the drum. This eliminated noise due to inadvertent operator movement of the probe and reduced operator fatigue. A suitable means would be needed to hold the probe securely to the drum during a test. It may be advantageous to clamp the probe to the bottom lip of the drum which is in proximity to the bottom surface. This would allow detection without removing a drum from its pallet. Reasonable signal levels were also obtained, however, with the probe in contact with the drum sidewall at approximately 4 inches from the bottom surface. This shows that probe placement is somewhat flexible and can be better tailored to suit ease of field deployment.

Digital signal processing was beneficial in removing extraneous background spectral content. Unless the measurement background noise can be significantly reduced through control of the physical room conditions, stable probe attachment and digital signal processing, a simple signal peak threshold detection scheme, as currently used by this instrument, is not likely to be a useful indication of beetle activity as background noise impulses may create false positive indications of 
beetle activity. This will also obviously depend on the extent of beetle infestation and timing of feeding activity in a particular package under test. More sophisticated signal analysis techniques will need to be used in order to reduce the effects of the background noise at the scanning location. An acoustical noise survey of the likely scanning area would be necessary to determine if conditions will be favorable for this technique and if certain times of day would be more suitable than others.

It remains to be identified how long a package would need to be interrogated for reliable detection, but initial estimates ranged from $\sim 5$ to 30 minutes. A larger infestation would be detectable in a shorter time, but a longer test time would be needed to reliably detect smaller colonies with fewer total noises present. Testing thus far has been limited to an infested sample of 1 packaging. Further tests would need to be performed to characterize the amount of time needed to interrogate packages with reasonable certainty of the indicated results. Additional research may reveal methods that can be employed to improve the likelihood of detection with a greater understanding of drugstore beetle behavior and feeding patterns.

At present, the extent of infestation within the 9975 packages in storage is not known. Drugstore beetles have been identified in 2 packages at Hanford in 2007 and in 1 package in KAC in 2012. Without knowing the source of these infestations, the presence of additional infested packages cannot be ruled out, and minor infestations might not be readily identified by operators when a package is opened if they have not been trained to specifically look for evidence of beetles. With one of the Hanford packages recently examined following 5 years of known beetle activity, it can be postulated that fiberboard destruction does not proceed at a rapid pace; however, significant degradation will occur given enough time.

It is recognized that entering the $\mathrm{K}$ Area storage locations to test for beetles would entail some radiation exposure. Detection could be attempted on packages only when they are removed for verification, surveillance or other activities. In such cases, since the package is going to be opened for other purposes, detection could also be performed visually by operators trained to look for evidence of infestation. The advantage offered by this acoustic emission system would be identification of an infestation before the package is opened and beetles possibly escape and infest other packages. This system also offers the option for testing larger numbers of packages in situ, if the need to verify the absence of infestation is great enough to accept the associated radiation exposure.

Several options are available to reduce the potential radiation dose to personnel. Depending on the length of time required for a reliable scan, the system could be left in place while the operator relocates to a low dose area. It would also be possible with multiple handheld units and a laptop or possibly the larger 32-channel multiplexer unit (AEC Model AED-2000M) to make one entry to attach probes and initiate the scan sequence, then exit while the system sequences through scans of multiple packages. It may also be possible to utilize a wireless communications link to remote a monitoring console to a low dose area if constant monitoring of scanning is desired or necessary.

In addition to in situ interrogation of packages in storage, acoustic emission could be used to screen packages upon receipt in $\mathrm{K}$ Area. In cases of packages transferred out of $\mathrm{K}$ Area without opening, this technique would also provide added assurance of package integrity.

The cost of the basic hand-held insect detection kit is approximately $\$ 3700$, which includes the Acoustic Emission Detector software application that allows more flexible control of instrument settings and logging of measurement results and system status messages. The AED-2000M 32- 
channel multiplexer unit has an approximate cost of $\$ 15 \mathrm{~K}$ for the computer-based main console and $\$ 500$ each for the sensor probes.

\subsection{Conclusions}

Though limited, these tests have shown that this technique and acoustic emissions instrumentation are promising for detecting the presence of drugstore beetles. Additional work would be needed to improve the ease of detection, and to automate the signal processing to eliminate the need for human interpretation. Depending on the desired operational method of conducting package scans, a system could be developed to scan multiple packages in automated sequence or simply scan one package at a time. Unless scanning area background noise is sufficiently low, simple peak signal detection methods of beetle activity will not likely be successful and more advanced signal processing techniques and automated analysis will be needed. Several options have been presented to reduce operator radiation exposure during package scans. These suggested enhancements are feasible and can be achieved to develop a realistic detection capability for field use.

\subsection{Recommendations}

The following recommendations are provided for consideration as a path forward in the development of a suitable acoustic emission beetle detection system and methodology for field deployment:

1. Develop an operational methodology for scanning packages (one at a time, multiple packages in automated sequence, packages in storage locations, during routine surveillances and inspections, prior to shipping, upon receipt at the facility)

2. Perform a background noise survey in proposed facility locations for performing package scanning

3. Select and purchase best suited instrument(s) based on desired operational scanning methodology (single handheld unit, multiple handheld units, large multiplexer unit)

4. Develop an appropriate signal processing algorithm to reduce background noise effects and improve reliability of indicated scan results

5. Perform system automation enhancements to reduce operator involvement and provide for ease of field use (probe clamping mechanism, automated computer scan control and analysis, remote operator monitoring/control and communications link)

6. Conduct research on beetle feeding patterns and behavior to maximize likelihood of detection

7. Perform additional testing to determine required scan times dependent on desired level of confidence and minimum detectable level of beetle activity 


\subsection{References}

Loftin, B. M., Shuler, J. M., Bellinger, R. G., Abramczyk, G. (2008). Investigation of the Presence of Drugstore Beetles within Celotex Assemblies in Radioactive Material Packagings, WSRC-STI-2008-00288.

Loftin, B. M., Shuler, J. M. (2010). Proceedings of the $36^{\text {th }}$ Annual Waste Management Conference - WM2010: Investigation of Drugstore Beetles and Their Effects within Radioactive Material Shipping Packages. Phoenix, Arizona. Retrieved from http://www.wmsym.org/app/2010cd/wm2010/index.html

Acoustic Emission Consulting, Inc. (2003), Termite and Insect Pest Detection Kit [Product Specification]. Version 2.0. Retrieved from http://www.aeconsulting.com/pdf/termitekit.pdf 


\section{Distribution:}

T. W. Griffin, 705-K

D. L. Melvin, 705-K

R. J. Bayer, 705-K

E. R. Hackney, 705-K

B. A. Eberhard, 105-K

C. Zeigler, Jr., 105-K

J. E. Marra, 773-A

S. L. Tibrea, 730-A

G. E. Weeks, 730-A

J. S. Bellamy, 730-A

D. R. Leduc, 730-A

G. T. Chandler, 773-A

W. L. Daugherty, 773-A

K. A. Dunn, 773-41A

W. R. Hinz, 730-A 